\title{
The role of renal biopsy in small renal masses
}

\author{
Rodolfo Burruni, MD;' Benoit Lhermitte, MD;2 Yannick Cerantola, MD;1 Thomas Tawadros, MD; \\ Jean-Yves Meuwly, MD, ${ }^{3}$ Dominik Berthold, MD, ${ }^{4}$ Patrice Jichlinski, MD; Massimo Valerio, MD
}

'Department of Urology, Centre Hospitalier Universitaire Vaudois, Lausanne, Switzerland; ' 2 Department of Pathology, Centre Hospitalier Universitaire Vaudois, Lausanne, Switzerland; 3 Department of Radiology, Centre Hospitalier Universitaire Vaudois, Lausanne, Switzerland; ${ }^{4}$ Department of Oncology, Centre Hospitalier Universitaire Vaudois, Lausanne, Switzerland

Cite as: Can Urol Assoc J 2016;10(1-2):E28-33. http://dx.doi.org/10.5489/cuaj.3417

Published online January 14, 2016.

\section{Abstract}

Renal biopsy is being increasingly proposed as a diagnostic tool to characterize small renal masses (SRM). Indeed, the wide adoption of imaging in the diagnostic workup of many diseases had led to a substantial increased incidence of SRM (diameter $\leq 4 \mathrm{~cm}$ ). While modern ultrasound, computed tomography $(\mathrm{CT})$ and magnetic resonance imaging (MRI) techniques have high sensitivity for detecting SRM, none is able to accurately and reliably characterize them in terms of histological features. This is currently of key importance in guiding clinical decision-making in some situations, and in these cases renal biopsy should be considered.

In this review, we aim to summarize the technique, diagnostic performance, and predicting factors of nondiagnostic biopsy, as well as the future perspectives.

\section{Introduction}

The detection of renal masses has been constantly increasing in the past several years. ${ }^{1}$ The adoption of imaging within the diagnostic workup of patients with abdominal and/ or pelvic symptoms is the major reason for this increased incidence. At present, most renal masses are incidentally detected by means of imaging in the form of ultrasound (US), $\mathrm{CT}$, and MRI. However, except for large typical angiomyolipoma, these tests alone cannot accurately characterize renal tumours, especially in the case of SRM - defined as all renal masses with a diameter $<4 \mathrm{~cm} ; 40-70 \%$ of incidentally discovered renal tumours are SRM. ${ }^{2}$

As a consequence, SRM management is challenging and percutaneous renal biopsy is being increasingly proposed for tissue sampling to allow better characterization. In the past, the acceptance of renal biopsy has been limited in light of concerns about safety, accuracy, and, ultimately, impact on clinical decision-making. There are currently a number of reasons for which characterization of SRM by renal biopsy would potentially be a step forward in our management. First, $20-30 \%$ of SRM are benign and would not need active treatment if one would be able to accurately and reliably characterize them without extirpative surgery. ${ }^{3,4}$ Second, distinguishing the origin of renal tumour leads to obvious differences in management, whether the renal mass represents a primary malignancy or a secondary location of a distant malignancy. Third, in case of malignant renal tumour, distinguishing the histological subtype and aggressiveness might have an impact on treatment allocation. Partial nephrectomy is considered the gold standard for treatment of malignant SRM, although novel approaches are emerging in selected subgroups of patients. Active surveillance and ablation therapy, such as cryotherapy and radiofrequency, may represent valid alternatives in patients who are not fit or refuse surgery. In this review, we summarize the role of renal biopsy in SRM with particular focus on rationale, technique, diagnostic performance, and predicting factors of nondiagnostic biopsy, as well as future perspectives.

\section{Rationale for renal biopsy for small renal masses}

The rationale for renal biopsy is to provide a histological diagnosis in order to guide adequate management. Despite improvements in US, CT, and MRI, imaging alone is not sufficient for characterizing SRM. The introduction of contrastenhanced US (CEUS) using injectable microbubbles has substantially improved the use of US in renal masses. A recent meta-analysis including 880 patients assessed the diagnostic accuracy of CEUS in distinguishing benign from malignant renal masses. ${ }^{5}$ The authors found a sensitivity and specificity of $0.88(95 \% \mathrm{C}=0.85-0.90)$ and $0.80(95 \% \mathrm{Cl}=0.75-0.85)$, respectively. The area under the receiving operating characteristic curve was 0.92. However, the use of US seems to be closely related to the size of the lesion, with small lesions being very difficult to diagnose and characterized. ${ }^{6}$ Therefore, in SRM the role of CEUS alone is limited. 
Multiphasic multislice CT has been considered the standard imaging test for characterizing renal masses in the last three decades. A complete protocol includes unenhanced, arterial, nephrographic, and excretory phases. In one retrospective analysis, multiphasic CT had an accuracy of around $80 \%$ for distinguishing renal clear-cell carcinoma from other renal cell carcinoma sub-types and oncocytoma. ${ }^{7}$ However, these findings need to be verified prospectively, and multiphasic CT alone cannot be used, at present, for determining histological subtype or aggressiveness of SRM.

MRI performance is currently considered comparable to multiphasic CT for SRM characterization. MRI also has additional use in patients with SRM deemed indeterminate on US or multiphasic CT. ${ }^{8}$ The use of multiparametric MRI using functional sequences has further enhanced the role of MRI in renal masses assessment. Recently, multiparametric MRI has been used to distinguish renal cell carcinoma subtypes, as well as detect angiomyolipoma and oncocytoma.

Novel imaging modalities might also play a role. Early data show that SPECT/CT has specificity of $95 \%$ and sensitivity of $83 \%$ for distinguishing oncocytic tumours from renal cell carcinoma variants. ${ }^{9}$

Finally, the use of positron-emission tomography (PET) with labelled antibodies to differentiate clear-cell carcinoma from others SRM has been reported in a phase I trial. ${ }^{10}$ The results showed a sensitivity and specificity of $94 \%$ and $100 \%$, respectively.

Despite the evolution across imaging techniques, correct characterization cannot be reliably obtained with any one of these in SRM. When knowledge of histology might change management, renal biopsy should be contemplated.

\section{Renal biopsy technique}

Modern percutaneous renal biopsy is a standardized procedure with few complications reported. ${ }^{11}$ It is recommended to sample SRM with at least two in-target cores under US or CT guidance. While US has the advantage of real-time imaging guidance, CT is more useful for deeply located lesions. The procedure is performed in the outpatient setting under local anaesthetic and with no antibiotic coverage. Using a coaxial technique or direct puncture with a 17-Gauge cannula, 18-Gauge automatic or semi-automatic biopsy needles can be safely inserted for tissue sampling in a free-hand fashion. The advantage of the coaxial technique is that multiple needles can be inserted using only one needle tract for introducing the cannula. While it is not used systematically and cannot replace renal biopsy, fine-needle aspiration (FNA) may have an additional value in case of cystic lesions.

In the past, one of the concerns limiting the spread of renal biopsy was the possibility of seeding in the biopsy trajectory. Although few cases have been reported in the literature, ${ }^{5,12}$ no cases of seeding have been reported when a coaxial technique is used. ${ }^{2,13-21}$

Complication rate of the procedure is low, at around $1 \%$. Bleeding represents the most frequent complication, which usually results in a subcapsular or perinephric haematoma requiring no interventional treatment.

\section{Diagnostic performance}

A number of large series have recently assessed the diagnostic performance of renal biopsy in SRM (Table 1). Each series included a median of 105 patients (IQR 83-150) with a median tumour volume of $33 \mathrm{~mm}$ (IQR 27-40). When reported, a median of $89 \%$ of patients had solid lesions, with a minority of $11 \%$ presenting cystic lesions. The median rate of diagnostic renal biopsies was $86 \%$, with a diagnosis of malignancy in a median of $79 \%$. In other words, when performing biopsy, diagnosis could be obtained in over four patients out of five. Nondiagnostic biopsy is the result of either insufficient material to establish a diagnosis or the presence of normal renal parenchyma. This is not the same as absence of malignancy or presence of benign lesion, and additional characterization is needed, as nondiagnostic biopsy is usually the result of inaccurate sampling. Indeed, a recent study showed that repeat biopsy lead to a histological diagnosis in $83.3 \%$ patients in which initial biopsy was nondiagnostic..$^{20}$ It is important to note that most nondiagnostic biopsies occurred in patients presenting with cystic lesions, with a median of $29 \%$ nondiagnostic rate in this subgroup as compared to only $14 \%$ nondiagnostic biopsies in patients presenting solid lesions.

Diagnostic accuracy of renal biopsy - defined as the sum of true positives and true negatives divided by the total number of patients undergoing biopsy - has been determined using nephrectomy specimen as the reference test. Biopsy accuracy has been calculated with respect to different outcomes of interest, namely presence of malignancy, histological subtype, and Fuhrman grade. With respect to distinguishing malignant and benign lesions, the median accuracy of renal biopsy was excellent at $98 \%$, with an IQR ranging between $91-100 \%$. The diagnostic accuracy of renal biopsy in determining histological subtype varied between $87 \%$ and $97 \%$, with a median of $92 \%$. The ability to distinguish benign from malignant lesions and to determine the histological subtype of renal cell carcinoma is improved by using immunohistochemical and molecular techniques (Fig. 1).

The diagnostic accuracy in determining the Fuhrman grade was lower, and varied between $58 \%$ and $74 \%$, with a median of $72 \%$. It is important to note that grade heterogeneity is a common feature in renal carcinoma and might be the reason for the discrepancy between biopsy and final pathology. A recent study showed grade heterogeneity in 


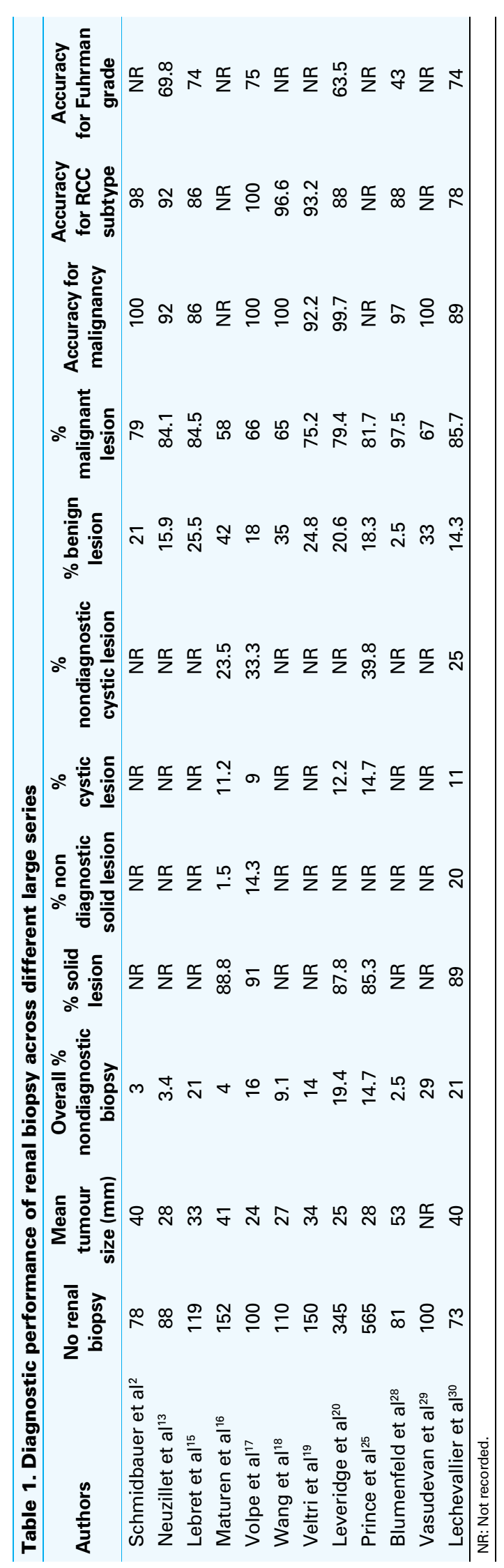

more than $80 \%$ of SRM and the presence of low-grade in up to $40 \%$ of assigned high-grade tumour. ${ }^{22}$ Considering these findings, an upgrade in Fuhrman grade from biopsy samples to final pathology can be expected. However, in those studies in which Fuhrman grade was divided in a dichotomous manner - low (I and II) and high (III and IV) grade — the accuracy was significantly higher. ${ }^{15}$

\section{Factors predicting nondiagnostic biopsy}

It is important to observe that a number of tumour and patient characteristics have been shown to be reliable predictors of nondiagnostic biopsy. Tumour type seems to be a strong a reliable predictor in most series. In one study, the presence of a cystic lesion was the most important predictor of nondiagnostic biopsy, with an odds ratio (OR) of 13.9 $(95 \% \mathrm{Cl}=3.78-50.7 ; \mathrm{p}<0.0001) .{ }^{20}$ Some have therefore proposed to add FNA to biopsy in case of cystic lesions in order to decrease the likelihood of nondiagnostic biopsy. ${ }^{23}$ In one study including 199 complex renal cysts, the combination of FNA and renal biopsy allowed definitive diagnosis in $87.9 \%$ cases, a figure that is in line with median rate of diagnostic biopsy. ${ }^{24}$

Another important predictor is tumour size. The smaller the lesion, the more likely it is to have nondiagnostic biopsy. The relationship between size and rate of diagnostic biopsy was quantified in one study including 345 patients undergoing renal biopsy. ${ }^{20}$ For every additional $1 \mathrm{~cm}$ in diameter, the OR for diagnostic biopsy was $3.11(95 \% \mathrm{C}=1.54-6.28$; $\mathrm{p}=0.002$ ). Lack of radiological enhancement or enhancement $\leq 20 \mathrm{HU}$ also seems to be a significant predictor of nondiagnostic biopsy, with a rate of $42 \%$ in one series. ${ }^{25}$ Finally, patient characteristics measured by skin to tumour distance were associated with a higher rate of nondiagnostic biopsy, with a threshold set at $13 \mathrm{~cm} .{ }^{25}$ Other characteristics, such as appearance (endophytic vs. esophytic), position (anterior vs. posterior), polarity (upper vs. lower pole), image guidance (US vs. CT), needle size, and operator experience, have been evocated by some, although these are yet to be proved significant predictors.

\section{Future perspectives}

In light of the positive diagnostic ratio (benefit/risk) of renal biopsy, the debate is around when to perform a biopsy and when it is not necessary to do so. The high diagnostic performance of renal biopsy (at least for differentiating malignant from benign lesions), the low morbidity, the impact on management, as well as the presence of predictors of nondiagnostic biopsy should be discussed with patients before performing renal biopsy. While some high-volume institutions proposing minimally invasive and conservative approaches are offering renal biopsy systematically, most experts agree that renal 


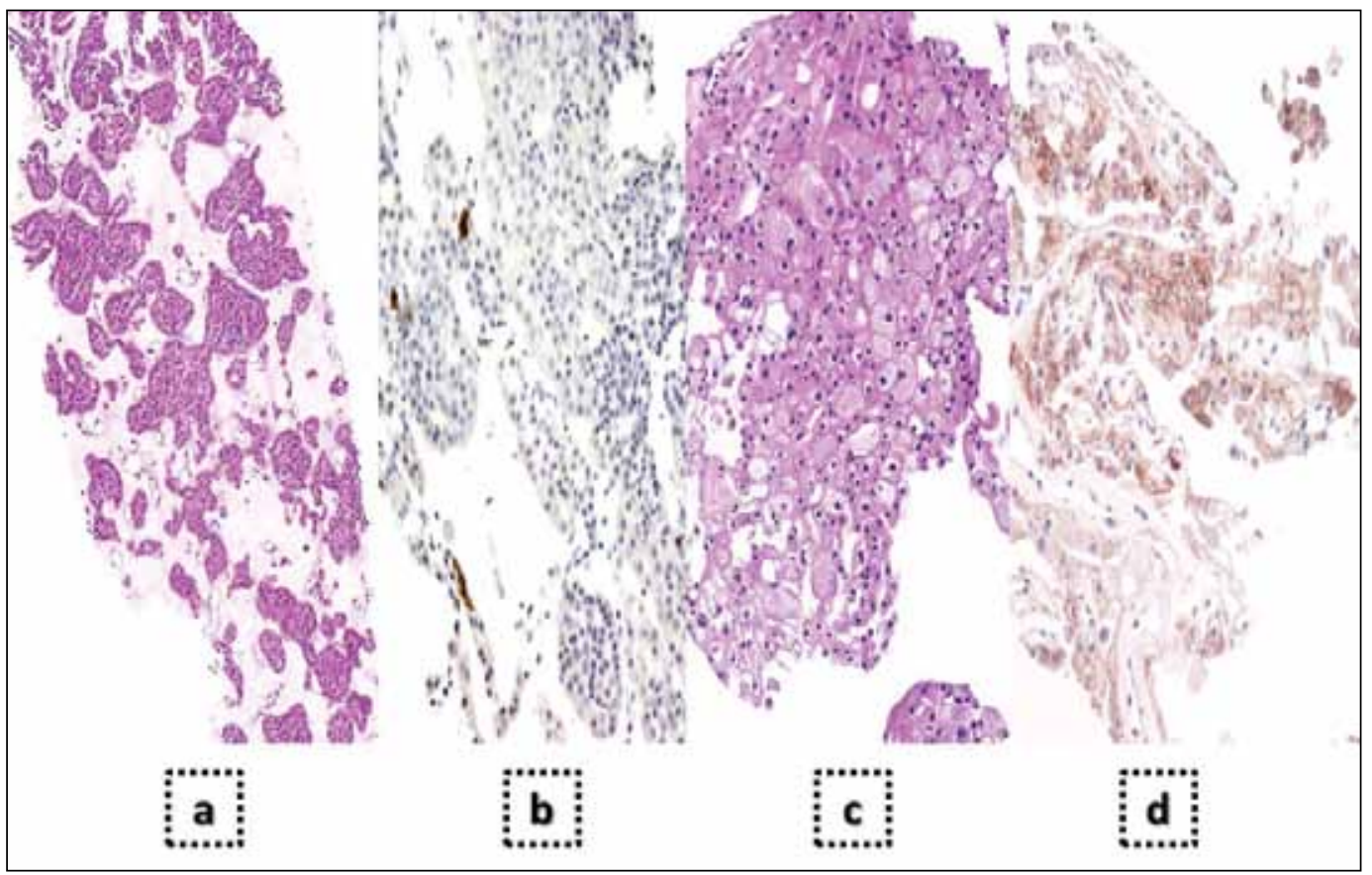

Fig. 1. Example of interest of immunohistochemistry in renal biopsy in order to distinguish oncocytoma (a-b) from cromophobe carcinoma (c-d). This distinction is of key importance to guide further management. Although both are eosinophilic tumours, oncocytoma cells usually show indistinct margins and cell nuclei may have nonhomogeneous shape and present large fibroedematous stroma (a). Cromophobe carcinoma cells usually present distinct margins, cells are smaller and nuclei are rounded (c). Both tumours express CK7, but the pattern is different. While oncocytoma show focal or limited expression in most cases (b), cromophobe carcinoma show intensive and extended CK7 expression (d).

biopsy should be performed in those situations in which a renal biopsy could change management. First, in patients with known extrarenal primary malignancy presenting with
SMR, percutaneous biopsy should be performed when diagnostic doubt exists between a primary renal malignancy and a secondary location (Fig. 2). Verification of tumour origin

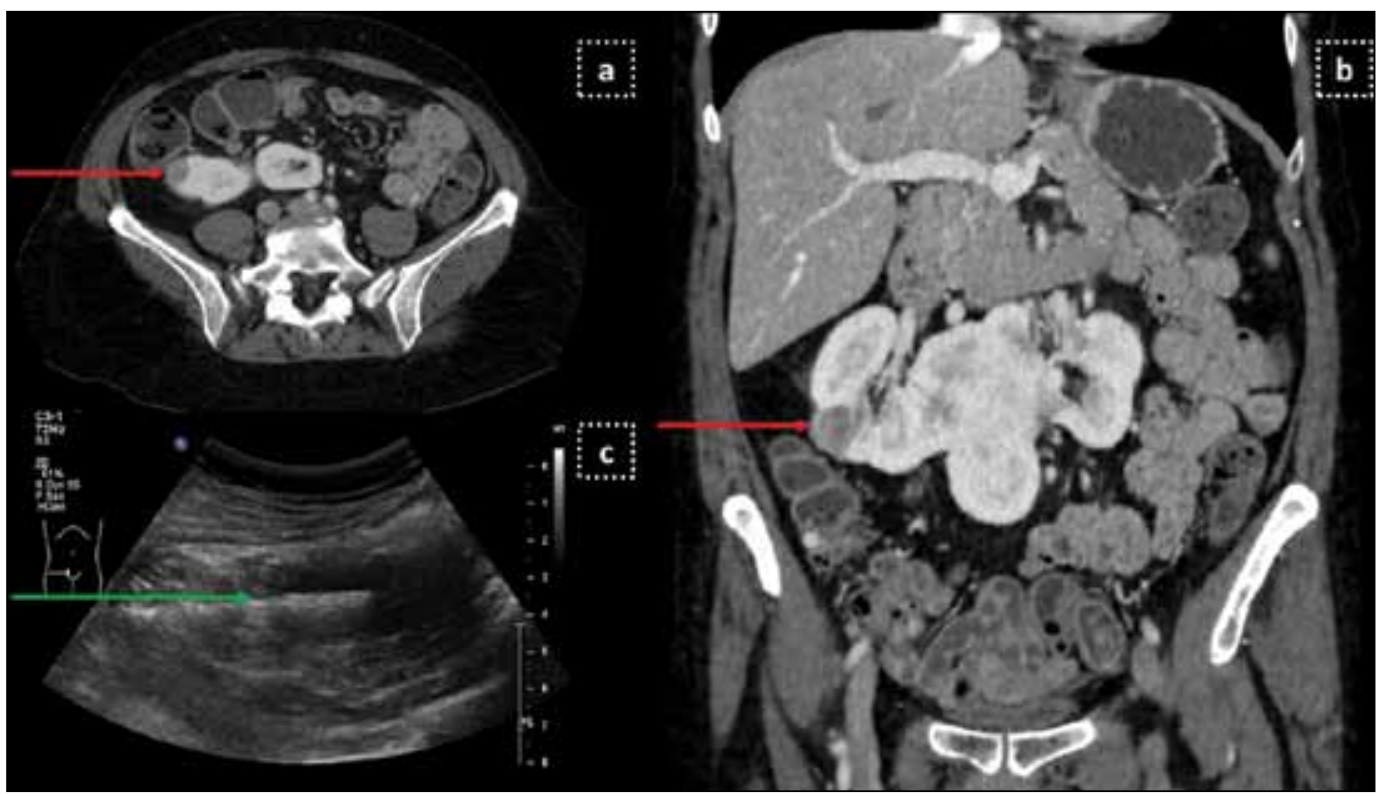

Fig 2. US guided biopsy in a 60-year-old woman with known anal carcinoma. (a) Staging abdominal CT scan shows a 2 $\mathrm{cm}$ hypodense mass (red arrow) on the right lateral part of a horseshoe kidney; (b) Coronal reconstructions depicting the nodule on the same CT scan; (c) US guided biopsy performed with an $18 \mathrm{G}$ needle (green arrow) revealed an epithelioid angiomyolipoma. 


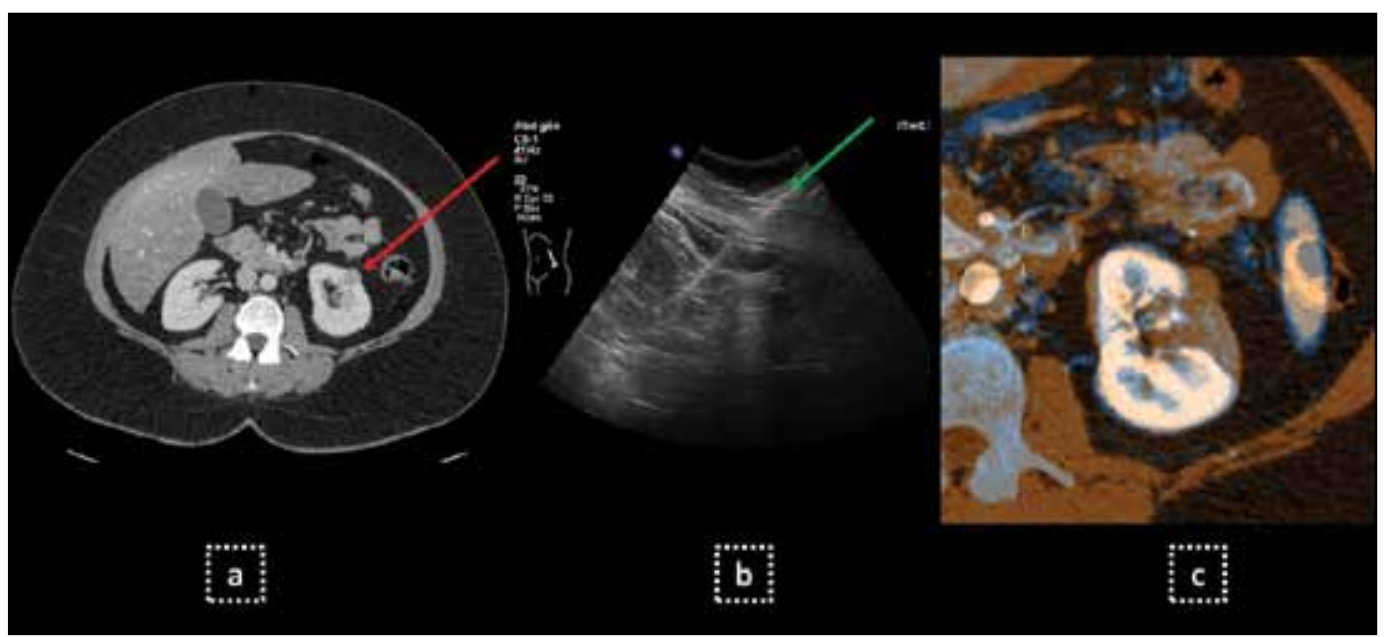

Fig. 3. US guided biopsy in an obese 42-year-old woman (BMI 33). (a) Incidentally identified small solid nodule of the left kidney (red arrow) on abdominal CT scan; (b) Percutaneous US-guided $18 \mathrm{G}$ needle biopsy (green arrow) revealed a chromophobe carcinoma; (c) Percutaneous radiofrequency was performed and three-months MRI (blue-blue coloured) compared to preoperative CT scan (orange-coloured) showed complete ablation.

has obvious implications for oncological management in this context. Second, in case of undetermined lesions or suspicion of benign tumours - such as oncocytoma and angiomyolipoma - biopsy is mandatory to characterize lesions and allow correct management (Figs. 3a, b). Third, patients considering ablative strategies or active surveillance should undergo renal biopsy upfront. This is essential for establishing diseasespecific risk, which cannot be extrapolated from imaging features, determining eligibility, and planning followup after treatment. Lack of tissue sampling at the outset of tissuepreserving approaches may lead to incorrect management ranging from treatment of benign disease to undertreatment of aggressive disease. Fourth, patients undergoing ablative strategies should undergo further biopsy during follow up, although there is no consensus as to whether biopsy should be performed systematically or only in case of suspicion of recurrence on imaging (Fig. 3c). ${ }^{26}$

The indications of renal biopsy might be expanded in the near future, pending assessment of novel immunohistochemistry, cytogenetic, and molecular markers. These markers could help improve biopsy accuracy for histological subtype identification and for predicting disease-specific survival. For instance, extracting RNA and performing polymerase chain reaction (PCR) has been shown to considerably increase the diagnostic accuracy of renal biopsy in defining histological subtypes. ${ }^{23}$ Similar findings were observed when fluorescence in situ hybridization (FISH) analysis was added to standard histological assessment. Some studies have equally shown that integrating cytogenetic information to existing prognostic factors could lead to a nomogram having an accuracy of 0.89 for predicting disease-specific survival. ${ }^{27}$ If these findings are confirmed, renal biopsy might be used more frequently to guide more personalized management.

\section{Conclusion}

Renal biopsy is technically safe, has good diagnostic performance with virtually no oncological risk. When knowledge of histological features of SRM might drive management, renal biopsy should be offered to all patients. The adoption in a clinical setting of novel markers might further expand the role of renal biopsy in SRM.

Competing interests: The authors declare no competing financial or personal interests.

This paper has been peer-reviewed.

\section{References}

1. Volpe A, Cadeddu JA, Cestari A, et al. Contemporary management of small renal masses. Eur Urol 2011;60:501-15. http://dx.doi.org/10.1016/i.eururo.2011.05.044

2. Schmidbauer J, Remzi $M$, Memarsadeghi $M$, et al. Diagnostic accuracy of computed tomography-guided percutaneous biopsy of renal masses. Eur Urol 2008;53:1003-11. http://dx.doi.org/10.1016/i. eururo.2007.11.041

3. Frank I, Blute ML, Cheville JC, et al. Solid renal tumors: An analysis of pathological features related to tumour size. J Urol 2003;170:2217-20. http://dx.doi.org/10.1097/01.ju.0000095475.12515.5e

4. Remzi $M$, Katzenbeisser $D$, Waldert $M$, et al. Renal tumour size measured radiologically before surgery is an unreliable variable for predicting histopathological features: Benign tumours are not necessarily small. BJU Int 2007;99:1002-6. http://dx.doi.org/10.1111/i.1464-410X.2007.06758.x

5. Wang $C, Y_{u} C$, Yang $F$, et al. Diagnostic accuracy of contrastenhanced ultrasound for renal cell carcinoma: A meta-analysis. Tumour Biol 2014;35:6343-50. http://dx.doi.org/10.1007/s13277-014-1815-2

6. Jamis-Dow CA, Choyke PL, Jennings SB, et al. Small $(\leq 3 \mathrm{~cm})$ renal masses: Detection with CT versus US and pathologic correlation. Radiology 1996;198:785-8. http://dx.doi.org/10.1148/radiology.198.3.8628872

7. Young JR, Margolis D, Sauk S, et al. Clear cell renal cell carcinoma: Discrimination from other renal cell carcinoma subtypes and oncocytoma at multiphasic multidetector CT. Radiology 2013;267:444-53. http://dx.doi.org/10.1148/radiol.13112617

8. Willatt JM, Hussain HK, Chong $S$, et al. MR imaging in the characterization of small renal masses. Abdominal Imaging 2014;39:761-9. http://dx.doi.org/10.1007/s00261-014-0109-x 
9. Gorin MA, Rowe SP, Baras AS, et al. Prospective evaluation of Tc-sestamibi SPECT/CT for the diagnosis of renal oncocytomas and hybrid oncocytic/chromophobe tumours. Eur Urol 2015. [Epub ahead of print] http://dx.doi.org/10.1016/i.eururo.2015.08.056

10. Divgi CR, Pandit-Taskar N, Jungbluth AA, et al. Preoperative characterisation of clear-cell renal carcinoma using iodine-124-labelled antibody chimeric G250 (124l-cG250) and PET in patients with renal masses: A phase I trial. Lancet Oncol 2007;8:304-10. http://dx.doi.org/10.1016/S1470-2045(07)70044-X

11. Volpe A, Kachura JR, Geddie WR, et al. Techniques, safety and accuracy of sampling of renal tumours by fine needle aspiration and core biopsy. J Urol 2007;178:379-86. http://dx.doi.org/10.1016/i. juro.2007.03.131

12. Mullins JK, Rodriguez R. Renal cell carcinoma seeding of a percutaneous biopsy tract. Can Urol Assoc J 2013;7E176-9.

13. Neuzillet $Y$, Lechevallier E, Andre M, et al. Accuracy and clinical role of fine needle percutaneous biopsy with computerized tomography guidance of small (less than $4.0 \mathrm{~cm}$ ) renal masses. J Urol 2004;171:1802-5. http://dx.doi.org/10.1097/01.ju.0000120147.51090.2bl

14. Shannon BA, Cohen RJ, de Bruto $\mathrm{H}$, et al The value of preoperative needle core biopsy for diagnosing benign lesions among small, incidentally detected renal masses. J Urol 2008;1801257-61;discussion 61. http://dx.doi.org/10.1016/i.juro.2008.06.030

15. Lebret T, Poulain JE, Molinie V, et al. Percutaneous core biopsy for renal masses: Indications, accuracy and results. J Urol 2007;178:1184-8;discussion 8. http://dx.doi.org/10.1016/i.juro.2007.05.155

16. Maturen KE, Nghiem HV, Caoili EM, et al. Renal mass core biopsy: Accuracy and impact on clinical management. AJR Am J Roentgenol 2007;188:563-70. http://dx.doi.org/10.2214/AJR.06.0220

17. Volpe A, Mattar K, Finelli A, et al. Contemporary results of percutaneous biopsy of 100 small renal masses: A single-centre experience. J Urol 2008;180:2333-7. http://dx.doi.org/10.1016/i.juro.2008.08.014

18. Wang R, Wolf JS Jr, Wood DP Jr, et al. Accuracy of percutaneous core biopsy in management of small renal masses. Urology 2009;73:586-90;discussion 90-1. http://dx.doi.org/10.1016/j.urology.2008.08.519

19. Veltri A, Garetto I, Tosetti I, et al. Diagnostic accuracy and clinical impact of imaging-guided needle biopsy of renal masses. Retrospective analysis on 150 cases. Eur Radiol 2011;21:393-401. http://dx.doi. org/10.1007/s00330-010-1938-9

20. Leveridge MJ, Finelli A, Kachura JR, et al. Outcomes of small renal mass needle core biopsy, nondiagnostic percutaneous biopsy, and the role of repeat biopsy. Eur Urol 2011;60:578-84. http://dx.doi. org/10.1016/i.eururo.2011.06.021
21. Breda A, Treat EG, Haft-Candell $L$, et al. Comparison of accuracy of 14- 18- and 20-G needles in ex-vivo renal mass biopsy: a prospective, blinded study. BJU Int 2010;105:940-5. http://dx.doi. org/10.1111/j.1464-410X.2009.08989.x

22. Ball MW, Bezerra SM, Gorin MA, et al. Grade heterogeneity in small renal masses: Potential implications for renal mass biopsy. J Urol 2015;193:36-40. http://dx.doi.org/10.1016/i.juro.2014.06.067

23. Volpe A, Finelli A, Gill IS, et al. Rationale for percutaneous biopsy and histologic characterisation of renal tumours. Eur Urol 2012;62:491-504. http://dx.doi.org/10.1016/i.eururo.2012.05.009

24. Lang EK, Macchia RJ, Gayle B, et al. CT-guided biopsy of indeterminate renal cystic masses (Bosniak 3 and 2F): Accuracy and impact on clinical management. Eur Radiol 2002;12:2518-24. http://dx.doi. org/10.1007/s00330-001-1292-2

25. Prince J, Bultman $E$, Hinshaw $L$, et al. Patient and tumour characteristics can predict nondiagnostic renal mass biopsy findings. J Urol 2015;193:1899-904. http://dx.doi.org/10.1016/i.juro.2014.12.021

26. Klatte $\mathrm{T}$, Kroeger N, Zimmermann U, et al. The contemporary role of ablative treatment approaches in the management of renal cell carcinoma (RCC): Focus on radiofrequency ablation (RFA), high-intensity focused ultrasound (HIFU), and cryoablation. World J Urol 2014;32:597-605. http://dx.doi.org/10.1007/ s00345-014-1284-7

27. Klatte $\mathrm{T}$, Rao PN, de Martino M, et al. Cytogenetic profile predicts prognosis of patients with clear cell renal cell carcinoma. J Clin Oncol 2009;27:746-53. http://dx.doi.org/10.1200/JC0.2007.15.8345

28. Blumenfeld AJ, Guru K, Fuchs $G \mathrm{~J}$, et al. Percutaneous biopsy of renal cell carcinoma underestimates nuclear grade. Urology 2010;76:610-3. http://dx.doi.org/10.1016/i.urology.2009.09.095

29. Vasudevan A, Davies RJ, Shannon BA, et al. Incidental renal tumours: The frequency of benign lesions and the role of preoperative core biopsy. BJU Int 2006;97:946-9. http://dx.doi.org/10.1111/i.1464410X.2006.06126.x

30. Lechevallier E, Andre M, Barriol D, et al. Fine-needle percutaneous biopsy of renal masses with helical CT guidance. Radiology 2000;216:506-10. http://dx.doi.org/10.1148/radiology.216.2.r00au01506

Correspondence: Dr. Rodolfo Burruni, Department of Urology, Centre Hospitalier Universitaire Vaudois, Lausanne, Switzerland ; rodolfo.burruni@chuv.ch 